Condensed Matter Physics, 1999, Vol. 2, No. 1(17), p. 75-79

GOJDEMSED

喟A

PINTSESS

\title{
Fluctuational dynamics and the structure factor of nonlinear reactive systems on a $1 \mathrm{D}$ lattice
}

\author{
O.I.Gerasimov, N.N.Khudyntsev \\ Odesa State Hydrometheorological Institute, \\ 100 Lvivska Str., 270011 Odesa, Ukraine
}

Received September 16, 1998

\begin{abstract}
Within the investigated model of a one-dimensional bi- and tri-molecular chemically reacted crystal, the asymptotic behaviour of the amplitude of a two-particle static structure factor (as a function of the crystal length) has been discovered. The nonlinear fluctuational scenario leads us to the conclusion as to the possibility of existence of an asymptotic metastable cluster fragmentation within initially homogeneous 1D systems. A connection between some possible effects and the properties of the fluctuations in reacting systems and reactive dynamics in a partially filled lattice is also shown.
\end{abstract}

Key words: chemical reactions, structure factor, $1 D$ lattice.

PACS: 61.20.Gy, 82.40.-g.

\section{Introduction}

One-dimensional models are known to be an effective tool for solving a variety of problems in statistical mechanics. In the past decades much attention in such areas as chemical reactions, random walks and aggregation problems has been paid to the role of dimensionality [1]. In particular, work carried out in Brussels by Nicolis, Provata, Prakash, Tretyakov and Turner has showed that restricting space to low dimension can cause deviations from the mean field behaviour, depending on the type of the nonlinearity involved. For instance, while the bimolecular reaction $A+X \longleftrightarrow 2 X$ shows the mean field behaviour on a 1D completely filled lattice, the trimolecular reaction $A+2 X \longleftrightarrow 3 X$ stabilizes in such a lattice in a nonequilibrium locally frozen asymptotic state in which the ratio of the average number $A$ to $X$ particles is a constant quite different from the mean-field value.

The work carried out within the framework of the IUAP project during our stay in Brussels focused on two topics: the properties of the fluctuations in the reacting systems and the study of reactive dynamics in a partially filled lattice. A 
manuscript summarizing the results is currently being prepared for publication in Europhysics Letters. We hereafter summarize the prinsipal steps and conclusions.

\section{Fluctuations in a completely filled 1D lattice}

Consider the bimolecular reaction $2 X \longleftrightarrow A+X$ on an ideal totally filled 1D lattice of $M$ sites, bearing in mind that a given species can only react with its nearest neighbours and that particles cannot overlap. We adopt as an initial condition a uniform configuration containing only $X$ particles. Since at equilibrium all the positive configurations of $A$ of $X$ particles, except the one of a lattice filled completely by $A$, can be generated from this initial condition, the probability distribution $g_{M}\left(N_{A}\right)$ is given by

$$
g_{M}\left(N_{A}\right)=\left(\begin{array}{c}
M \\
N_{A}
\end{array}\right) / \sum_{N_{A}=0}^{M-1}\left(\begin{array}{c}
M \\
N_{A}
\end{array}\right)=2^{1-M}\left(\begin{array}{c}
M \\
N_{A}
\end{array}\right)
$$

with $N_{A}+N_{X}=M$.

From (1) one recovers asymptotically $(M \rightarrow \infty)$ the previous result of Nicolis et al. $r=\left\langle N_{A}\right\rangle /\left\langle N_{X}\right\rangle=1$. Furthermore, one can compute a covariant matrix of the fluctuations around the mean particle numbers

$$
\begin{gathered}
\left\langle\delta N_{A}^{2}\right\rangle=\left\langle N_{A}^{2}\right\rangle-\left\langle N_{A}\right\rangle^{2}=-\frac{M}{4}, \\
\left\langle\delta N_{A} \delta N_{X}\right\rangle=-\left\langle\delta N_{A}^{2}\right\rangle=\frac{M}{4},
\end{gathered}
$$

etc.

Coming now to the trimolecular model and adopting the same initial condition, one can easily see that because of the geometric constrains involved, for each given $N_{A}$, at least $N_{A}-1$ sites cannot be occupied by $A$ particles. The probability distribution replacing (1) is thus

$$
g_{M}\left(N_{A}\right)=\frac{\left(\begin{array}{c}
M-1-N_{A} \\
N_{A}
\end{array}\right)}{\sum_{N_{A}=0}^{M-1}\left(\begin{array}{c}
M-1-N_{A} \\
N_{A}
\end{array}\right)}=\frac{2^{M} \sqrt{5}}{(1+\sqrt{5})^{M}-(1-\sqrt{5})^{M}}\left(\begin{array}{c}
M-1-N_{A} \\
N_{A}
\end{array}\right) .
$$

Again, the expression reproduces the value $\left\langle N_{A}\right\rangle /\left\langle N_{X}\right\rangle \approx 0.38$ obtained previously by Nicolis et al. However, one is now also in the position to compute the properties of the fluctuations. For instance, one finds

$$
\frac{1}{M}\left\langle\delta N_{X} \delta N_{A}\right\rangle=\frac{2}{5(1+\sqrt{5})}\left[\frac{2}{\sqrt{5}(1-\sqrt{5})}-\frac{1}{5}\right]
$$




\section{Partially filled lattice}

Next we allow for vacancies in the lattice, starting with an initial configuration in which $N_{X}$ particles $\left(N_{X}<M\right)$ are distributed randomly among the $M$ sites available. We also introduce three auxiliary variables:

- the number of nearest neighbours pairs occupied simultaneously by $X$ particles $-N_{X X}$,

- the number of nearest neighbours pairs of which only one is occupied by $X$ particles $-N_{0 X}$,

- the number of nearest neighbours pairs both of which are empty $-N_{00}$.

The following relations between these variables are easily established

$$
\begin{gathered}
2 N_{X X}+N_{0 X}=2 N_{X}, \\
2 N_{00}+N_{0 X}=2\left(M-N_{X}\right),
\end{gathered}
$$

showing that of these three variables only one can be chosen independently, say $N_{X X}$. The number of different configurations of $X$ particles with only $N_{X X}$ pairs is then

$$
G_{M}\left(N_{X}, N_{X X}\right)=\left(\begin{array}{c}
N_{X} \\
N_{X}-N_{X X}
\end{array}\right)\left(\begin{array}{c}
M-N_{X} \\
N_{X}-N_{X X}
\end{array}\right)
$$

Since $A$ particles can only be generated from the configurations involving continuous $X$ particles, the conditional probability to find $N_{A}$ particles in the system is $\left(\begin{array}{c}N_{X X} \\ N_{A}\end{array}\right)$ (up to factor), and the equilibrium distribution of the lattice is, for the bimolecular model,

$$
g_{M}\left(N_{A}, N_{X}\right)=\sum_{N_{X X}=0}^{N_{X}-1} 2^{-N_{X X}}\left(\begin{array}{c}
N_{X} \\
N_{X}-N_{X X}
\end{array}\right)\left(\begin{array}{c}
M-N_{X} \\
N_{X}-N_{X X}
\end{array}\right)\left(\begin{array}{c}
N_{X X} \\
N_{A}
\end{array}\right) .
$$

This expression can be reduced to a form exhibiting a confluent hypergeometric function and used to calculate the fluctuations of the number of particles. The principal result of this analysis is that now the fluctuations behave anomalously

$$
\left\langle\delta N_{A} \delta N_{X}\right\rangle \approx \lambda^{2} M^{2}
$$

where $\lambda=N_{X}^{(0)} / M$ is an initial filling fraction.

\section{Structure factor}

To get an idea of the type of spatial inhomogeneities locally created in the lattice we evaluated the structure factor of the system, a quantity the additional interest of which is in its experimental accessibility. 
Let $g$ be a wave number associated with the inhomogeneities. The structure factor is then

$$
S_{A X}(g)=\sum_{l=-\infty}^{\infty} \sum_{l^{\prime}=-\infty}^{\infty} \mathrm{e}^{\mathrm{i} g\left(l-l^{\prime}\right)}\left\langle\sum_{n \in N_{A}} \delta_{n l}^{k r} \sum_{m \in N_{X}} \delta_{m l^{\prime}}^{k r}\right\rangle,
$$

where $l$ and $l^{\prime}$ denote the lattice sites. Performing the summations over $l$ and $l^{\prime}$ we obtain

$$
S_{A X}(g)=\frac{1}{2(1-\cos g)}\left\langle\left(1-\mathrm{e}^{\mathrm{i} g N_{A}}\right)\left(1-\mathrm{e}^{\mathrm{i} g N_{X}}\right)\right\rangle .
$$

In the long wavelength ("hydrodynamic") limit $g \rightarrow 0$ this expression reduces to

$$
S_{A X}(g) \sim\left\langle\delta N_{A} \delta N_{X}\right\rangle-\Gamma g^{2} .
$$

The $g$-dependence of this function reflects the existence of a spatial variability. However, since the extremum of $S_{A X}$ is at $g=0$, no preferred length scale emerges. The situation is likely to change in the trimolecular model which is currently under investigation.

\section{Acknowledgements}

The authors would like to thank J.W.Turner for useful discussions. O.I.G. thanks the Belgian Federal Office for Scientific, Technical and Cultural Affairs for the financial support of his research under the Poles d'Attraction Interuniversitaire Program. He expresses gratitude to the Center for Nonlinear Phenomena and Complex Systems at Universite Libre de Bruxelles, Belgium, for the financial support, hospitality and fruitful cooperation.

\section{References}

1. Nicolis G., Prigogine I. Self-organization in Nonequilibrium Systems. New York, Wiley, 1977.

2. Provata A., Turner J.W., Nicolis G. Nonlinear chemical dynamics in low dimensions: an exactly soluble model. // Journ. Stat. Phys., 1993, vol. 70, p. 1195-1213.

3. Prakash S., Nicolis G. Dynamics of fluctuations in a reactive system of low spatial dimension. // Journ. Stat. Phys., 1996, vol. 82, p. 297-322.

4. Tretyakov A., Provata A., Nicolis G. Nonlinear chemical dynamics in low-dimensional lattices and fractal sets. // Journ. Phys. Chem., 1995, vol. 99, p. 2770-2776.

5. Monthus C., Hilhorst H.J. The pair correlation function in a randomly sequentially filled 1D lattice. // Phisica A, 1991, vol. 175, p. 263-274.

6. Hill T.L. Statistical Thermodynamics. London, Addison Wesley, 1960.

7. Feller W. An Introduction to Probability Theory and Its Applications. New York, Wiley, 1971.

8. Prudnicov A.P., Brychkov Yu.A., Marichev O.J. Integrals and Series (vol. 1-3). New York, Gordon and Breach Sci. Pub., 1990. 
9. Gradstein J.C., Ryzhik J.M. Tables of Integrals, Sums, Series and Products. Moscow, Nauka Pub., 1963 (in Russian).

\title{
Флуктуаційна динаміка та структурний фактор нелінійної системи з реакціями на одновимірній гратці
}

\author{
Герасимов О.І., Худинцев М.М.
}

Одеський гідрометеорологічний інститут, 270011 Одеса, вул. Львівська, 100

Отримано 16 вересня 1998 р.

Запропонована модель одновимірного кристалу з дво- та тримолекулярними хімічними реакціями, для якої досліджена асимптотична поведінка амплітуди двочастинкового статичного структурного фактору (як функції довжини кристала). Аналіз нелінійного характеру флуктуацій свідчить про принципову можливість існування асимптотичних метастабільних станів у модельному одновимірному кристалі з однорідними початковими умовами. Також досліджено зв'язок між флуктуаційними властивостями та динамікою систем, що реагують, та деякими ефектами, що можуть виникати на цілком заповнених гратках.

Ключові слова: хімічні реакції, структурний фактор, одновимірна гратка.

PACS: $61.20 . G y, 82.40 .-g$. 
